Saito A, Kawanishi H, Yamashita AC, Mineshima M (eds): High-Performance Membrane Dialyzers.

Contrib Nephrol. Basel, Karger, 2011, vol 173, pp 191-195

\title{
Commercially Available High- Performance Membrane Dialyzers and Several Special Kinds on the Japanese Market (as of April 30, 2011)
}

\section{A.C. Yamashita}

Department of Human and Environmental Science, School of Engineering, Shonan Institute of Technology, Tsujido-Nishikaigan, Fujisawa, Kanagawa, Japan 


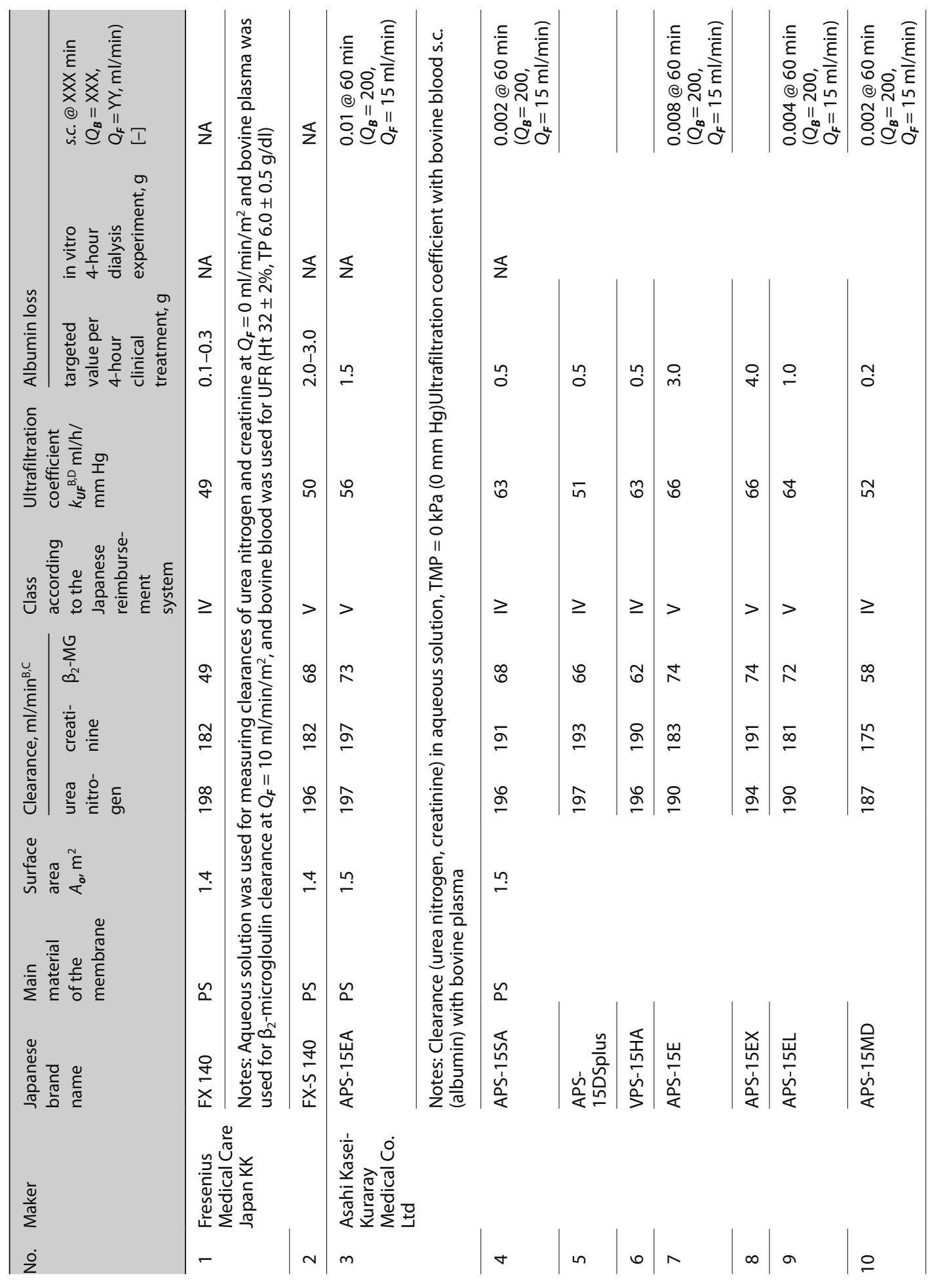




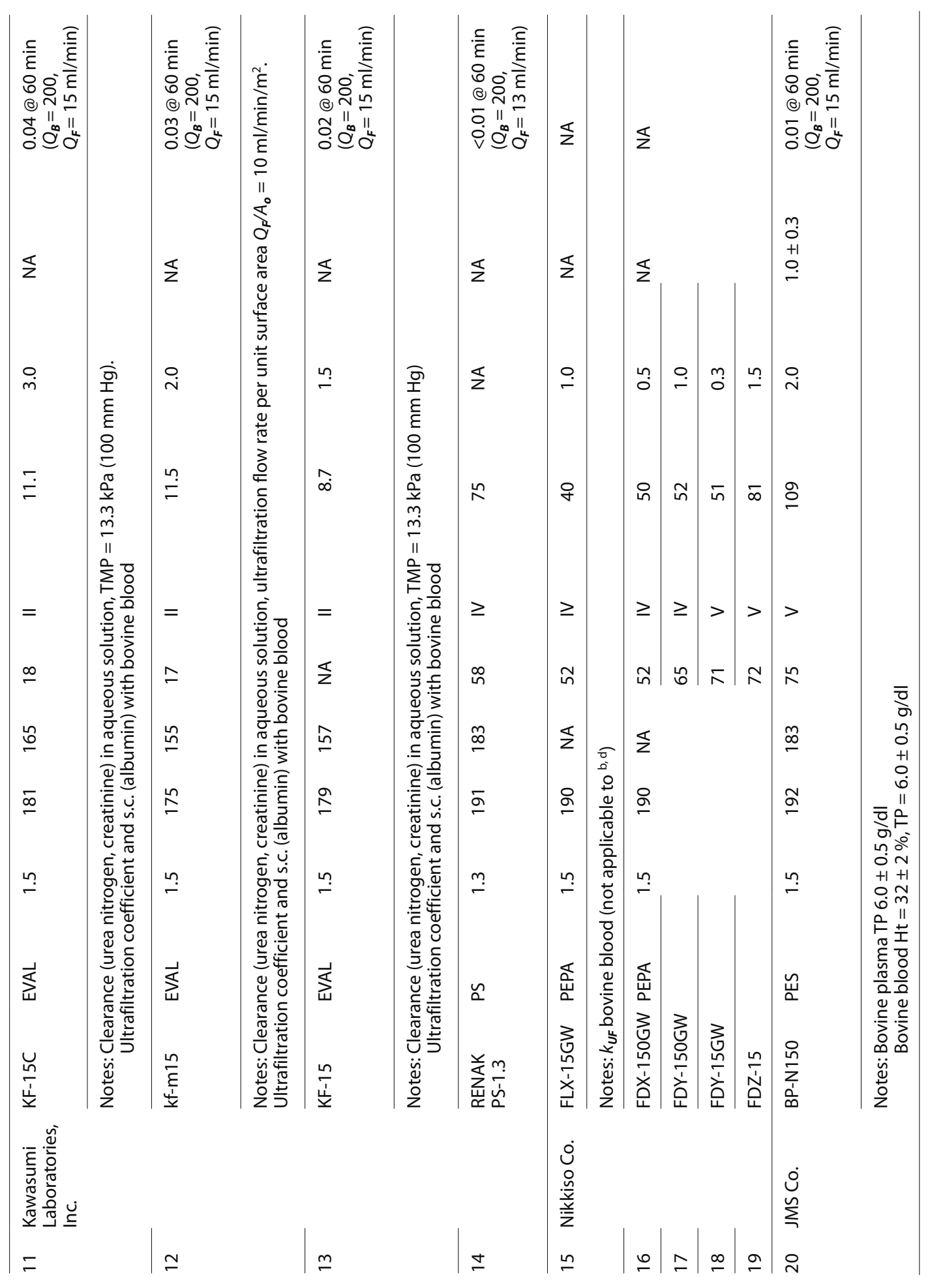




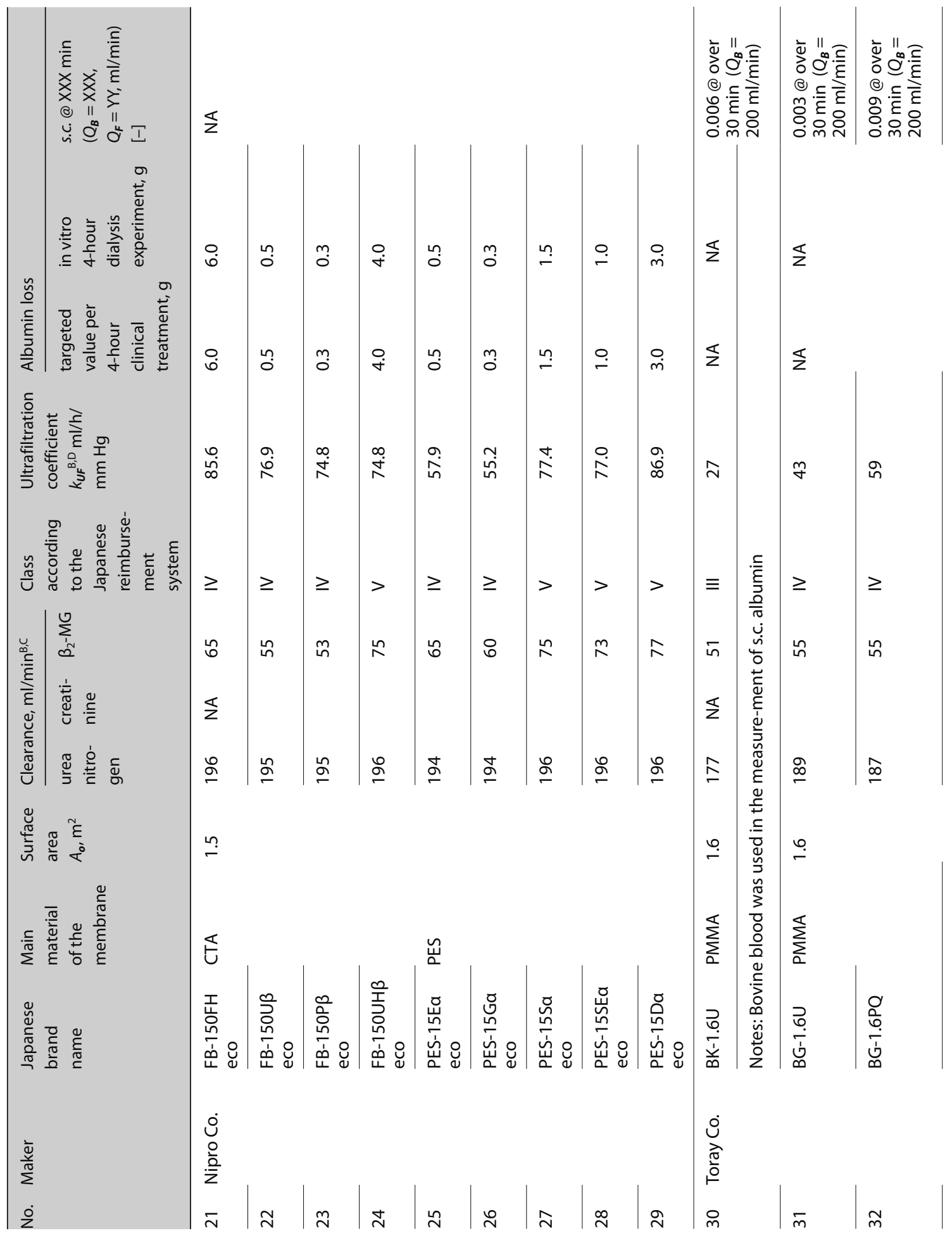



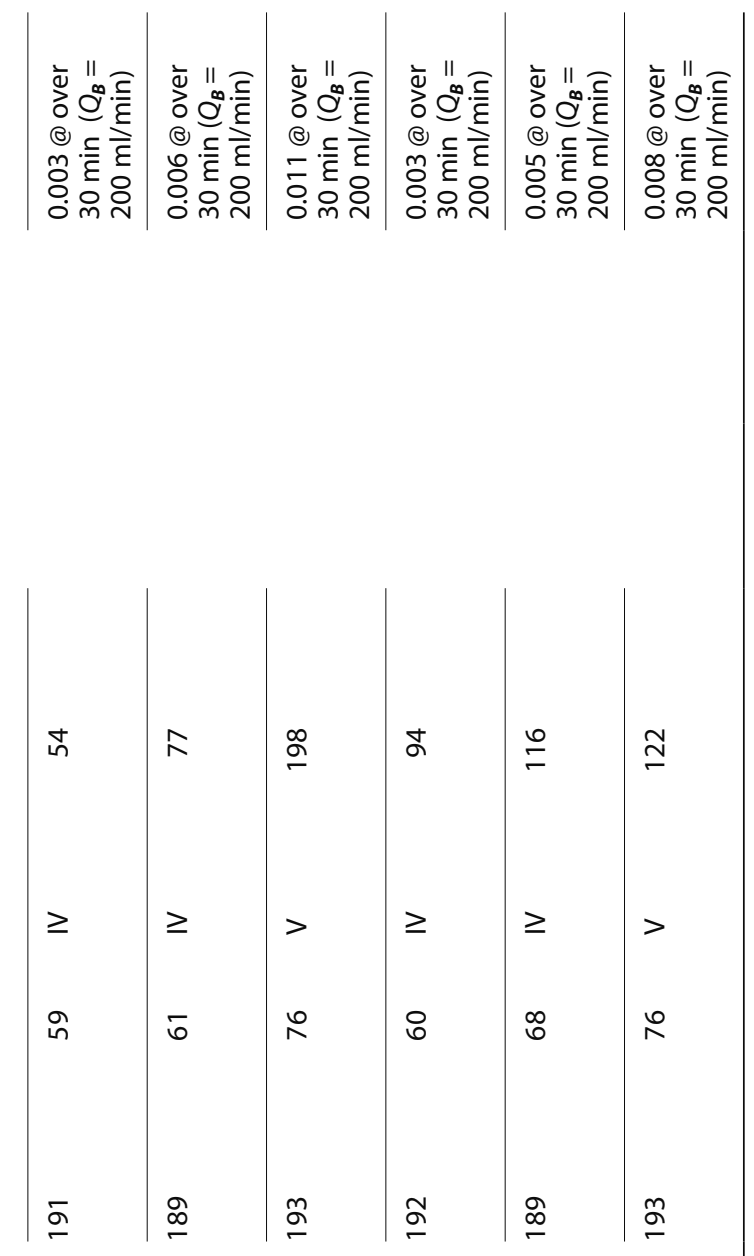

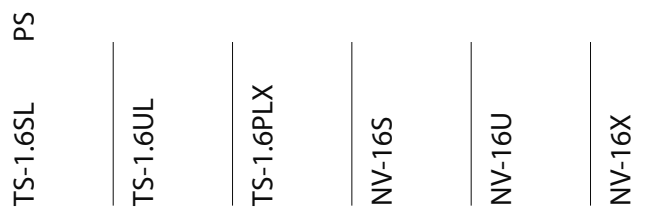

$\mid$\begin{tabular}{l|l|l|l|l}
$m$ & $m$ & $\infty$ & $\infty$ \\
$m$ & $\infty$ & $\infty$
\end{tabular}

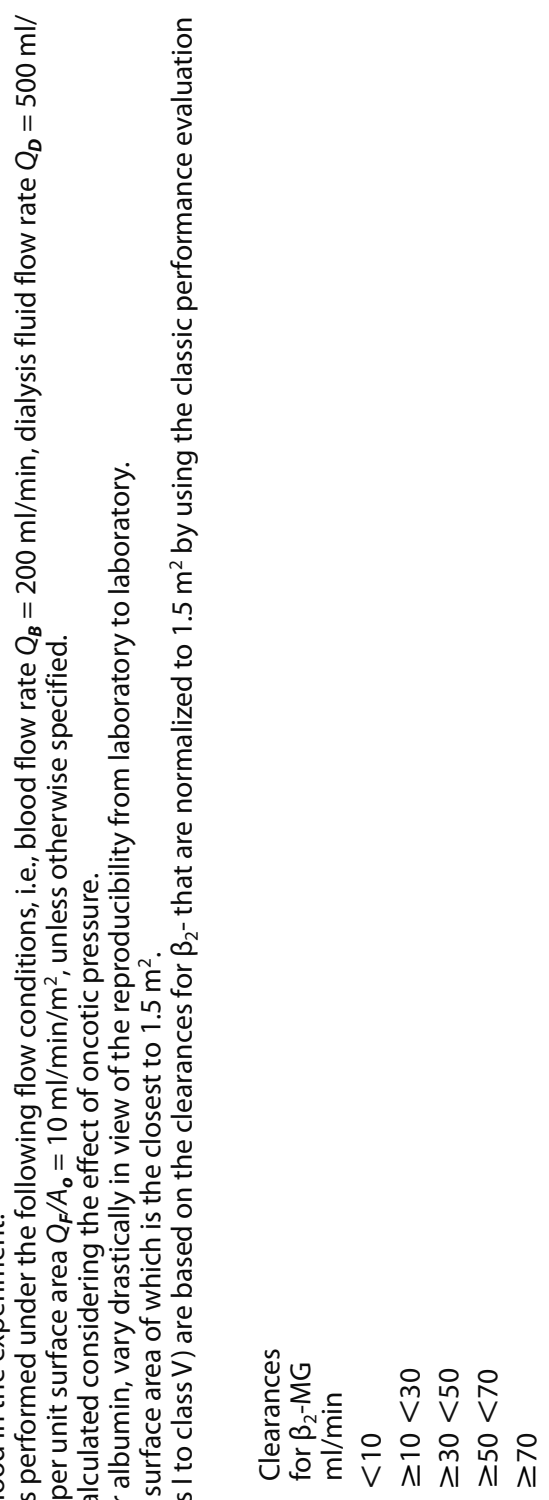

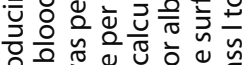

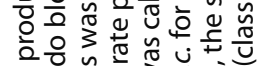

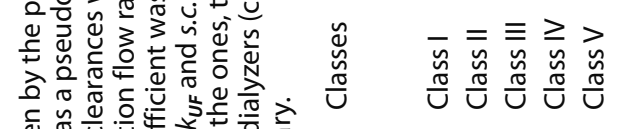

